\title{
Facilitators' use of a communication device following children's aided turns in everyday interaction
}

\author{
Maja Sigurd Pilesjö ${ }^{1}$ and Niklas Norén ${ }^{2}$ \\ ${ }^{1}$ University of Southern Denmark, Odense, Denmark \\ ${ }^{2}$ Uppsala University, Uppsala, Sweden
}

\begin{abstract}
This conversation analysis study investigates facilitators' simultaneous use of speech and aided means in instructional interaction with children with complex communication needs (CCN), who use aided communication in an everyday setting. The participants were children with severe speech impairments and their everyday communication partners. The analysis focused on facilitators' aided turns immediately following aided turns by the children, within so-called retro-sequences. Retro-sequences were found in interactions involving four out of nine children. The facilitators systematically combined a spoken turn with an aided turn, a speaking and pointing (SAP) practice. The pointing consisted of a single graphical word, mostly a noun. The multimodal practice generally highlighted, emphasized, or exposed graphical words that increased noticeability and understandability within the local context. Adult repeats were treated as requests for confirmation of a candidate understanding and were responded to by the child using vocal and embodied resources. Reformulations (recasts) were treated as profferings of candidate understandings and were responded to using the communication device. The findings indicate that the partner's use of a spoken and aided follow-up action shaped the immediate context for device use. The findings are relevant for the design of naturalistic interventions and may be used
\end{abstract}

\footnotetext{
Affiliations

${ }^{1}$ University of Southern Denmark, Odense, Denmark Email: msp@language.sdu.dk (corresponding author)

${ }^{2}$ Uppsala University, Uppsala, Sweden

Email: niklas.noren@edu.uu.se
} 
to improve treatment descriptions in augmentative and alternative communication (AAC) interventions.

\author{
KEYWORDS: AUGMENTATIVE AND ALTERNATIVE COMMUNICATION; SPEAKING AND \\ POINTING PRACTICE; CANDIDATE UNDERSTANDINGS; REQUESTS FOR \\ CONFIRMATION; RETRO-SEQUENCES; REPEAT; REFORMULATION; RECASTS; \\ CONVERSATION ANALYSIS
}

\title{
Introduction
}

This is a study of communication partners' (facilitators') naturalistic instruction in the field of augmentative and alternative communication (AAC). In this context, naturalistic instruction signifies settings where the facilitator talks to the child with a pedagogical language stimulation goal, but in a natural setting. Today, a highly recommended strategy is that facilitators carry out instruction in natural conversational contexts, using aided means simultaneously with their own speech (Binger and Light, 2007). A growing body of literature strongly supports the incorporation of facilitators' use of aided means in intervention programs for persons with complex communication needs (CCN) (for recent overviews of intervention research, see Biggs, Carter, and Gilson, 2018; Sennott, Light, and McNaughton, 2016). Although the strategy of facilitators using aided means is recommended, it is not well delineated. There is a lack of clarity as to how the strategy actually plays out in everyday interactions, and researchers have suggested that there are several types of instructional strategies and, moreover, questioned whether it is possible to compare studies when the strategies are so imprecisely described. To address this problem, the current study uses conversation analysis (CA) as a research tool, in order to investigate instances where the facilitator uses aided means immediately following an aided turn by the child, in a so-called retrosequence (Schegloff, 2007). Retro-sequences are sequences achieved when a speaker responds to a previous action and constructs it as noticeable and repairable in retrospect, without the response being projected by the previous ongoing sequence (Schegloff, 2007).

\section{Previous work on the effects of facilitators' use of aided means}

The theoretical underpinnings of the body of research mentioned above are drawn from developmental psychology, where exposing children to language and language use (or input) is understood as crucial to their language development (e.g., Kaiser and Roberts, 2011; Tomasello, 2003). Children with CCN rely on communicative resources other than speech for language production 
(e.g., body movement, vocalizations, manual signs, graphic symbols on low-tech communication devices or high-tech communication devices). Compared to children with typical development, children with CCN are significantly less exposed to models of language use in their own communicative modality (Romski and Sevcik, 2003).

Studies within the AAC field on the effects of facilitators' use of aided means have investigated children at a range of ages and with different diagnoses, from autism spectrum disorders to different kinds of developmental disabilities (e.g., Binger and Light, 2007; Romski and Sevcik, 2003; for a systematic review, see also Biggs, Carter, and Gilson, 2018; Sennott, Light, and McNaughton, 2016). The majority of the studies have found specific positive effects on the intra-cognitive abilities of the individual with CCN when aided means were used by the communication partner. These studies mainly employed quantitative behavioristic research methods, which measured how this practice has influenced the child with CCN's communicative and linguistic abilities in prespecified ways. Regarding semantics and syntax, studies showed that facilitators' use of aided means can improve expressive and receptive vocabulary and language comprehension (Harris and Reichle, 2004; Romski and Sevcik, 2003). In the same vein, the strategy resulted in an increase in linguistic complexity (morphology and syntax) (Binger and Light, 2007; Romski and Sevcik, 2003). Another positive effect has been found in pragmatic abilities, for instance, turn-taking (Kent-Walsh, Binger, and Hasham, 2010). Additionally, at a societal level, the use of AAC systems by others may make them socially more acceptable (Romski and Sevcik, 2003). A few authors also point to a possible disadvantage of the strategy, in that the learner's attention resources may be split between the spoken word, the graphic item, and the referent, rather than between the spoken word and the referent only (Blockberger and Sutton, 2003). Mainly, however, there is growing evidence that facilitators' use of aided means promotes language and communication development for persons with CCN (Binger and Light, 2007; Lund and Light, 2003; Romski and Sevcik, 2003; Sennott, Light, and McNaughton, 2016).

The strategy of using the same communicative means is assigned a variety of terms that draw on their functions as stimulating input techniques: augmented input (Alant, Alshubrumi, and Sun, 2017; Allen, Schlosser, Brock, and Shane, 2017; Romski and Sevcik, 2003), aided language stimulation (Acheson, 2006; Goosens, 1989), aided language modeling (Drager et al., 2006), and aided AAC modeling (Binger and Light, 2007). Jonsson, Kristoffersson, Ferm, and Thunberg (2011) also use the more descriptive term point-talking for the actual practice.

The term modeling has been used in a wide sense, including the use of aided means in all sequential contexts (as initiations, i.e. actions preceding the 
child's aided turn and retro-sequences, i.e. actions following the child's aided turn). The concept of modeling as language input is widely used in various fields of not only language learning and speech and language therapy in general, but also within the field of AAC. Current AAC intervention programs, however, are rarely based on detailed analysis of practices used in actual social interaction. In addition, the few examples offered in the literature are limited in scope and detail. The descriptions commonly highlight the simultaneous use of speech and aided means as a key feature of the strategy. For example, Romski and Sevcik (2003) describe the strategy as referring to when a speaking partner says, 'Let's go read a book' and simultaneously indicates GO and BOOK on a communication device (p. 150). Also calling it modeling, Binger and Light (2007) describe the strategy as when 'the child points to the symbol MILK, then the adult says "More milk" while pointing to MORE and MILK' (p. 31). Binger, Maguire-Marshall, and Kent-Walsh (2011) analyze the use of 'recasts' with children's aided turns in an intervention context, but the examples are few, only glossed, and do not describe the interactional context. In a recent systematic review of AAC modeling intervention research, Sennott, Light, and McNaughton (2016) adhere to the wide definition of modeling and describe it as something that 'occurs when the communication partner points to, or in some way draws attention to vocabulary items in the AAC system at the same time as s/he speaks words with similar linguistic content' (p. 102). The review by Sennott and colleagues (2016) found that intervention programs, including modeling, had a positive effect on several areas (e.g., increase in turns, vocabulary, syntax, and morphology).

Some of the strategies associated with facilitators' methods of presenting language targets for learners focus on facilitators' actions following the child's turn. This is also the focus of the current study. In the field of language learning and language impairment, these strategies are commonly categorized as repetitions, recasts, and expansions, and numerous studies have investigated them. The categories are sometimes not clearly defined, and there may also be overlaps between them. Therefore, the efficiency of strategies covered by these terms is sometimes difficult to determine (Saxton, 2005). Hence, there are different definitions of the three concepts. Hepting and Goldstein (1996) define repetitions as achieved when the adult does an exact repeat of the child's utterance; recasts as the adult adjusting the child's utterance to a correct form; and expansions as the adult elaborating on the structure and adding elements to the child's utterance. Recasts are considered to have a number of advantages. Since one is talking about a topic of interest to the child, they gain the child's attention. There is a strong likelihood that the child will comprehend at least part of what is being said to them, since lexical items are being reflected back to them from their own utterance. The position immediately after the child's 
utterance provides a contrast to the child's utterance and is considered to give an ideal opportunity for the child to compare their utterance with the facilitator's utterance. In addition, recasts are viewed as a non-invasive and implicit way to invite correction of an utterance, instead of explicitly pointing out a mistake to the child (Saxton, 2005). These kinds of instruction strategies are implemented in naturalistic interaction contexts for children who are developing spoken language (Hepting and Goldstein, 1996).

In a recent study of different types of recasts in the field of AAC, Soto, Clarke, Nelson, Starowicz, and Savaldi-Harussi (2019) studied the effects of conversation-based intervention and the relationship between type of recast, child repair, and the spontaneous use of linguistic targets by the child. They classified recasts into two groups: (1) recast followed by a prompt to repair and (2) recast alone. By prompt, the authors meant verbal encouragement or pointing at the linguistic target on the communication device. The recasts not including a prompt were divided into three subgroups: a declarative recast (reformulation in a statement), a non-inverted interrogative recast (reformulation produced with rising intonation), and an interrogative choice (reformulation produced as two or more alternatives). Note that recast here refers to spoken means only. Furthermore, the study investigated whether the child's subsequent turn included a repair. The results indicated that repair varied according to recast type. The children repaired more frequently when they were prompted to do so and when the recast was an interrogative choice recast. The study also found that later spontaneous use of linguistic targets seemed to be positively related to conversational sequences of adult recasts followed by repair of the child.

\section{Conversation analysis research on augmentative and alternative communication}

Conversation analysis (CA) is used as a research method in the current study (see the section titled 'Analytical approach' for a description of CA). CA is a well-established method to investigate and describe atypical interaction involving adults and children with language and communication impairments (e.g., Friedland and Miller, 1999; Gardner, 2006; Lesser and Milroy, 1993) and in the field of AAC (e.g., Bloch and Wilkinson, 2004; Clarke and Bloch, 2013; Norén, Samuelsson and Plejert, 2013). Conversation analysis research has contributed to drawing attention to the process of interaction, instead of only to the person with the communicative impairment. Conversation analysis studies have found that communication devices operate to support the conversational activity, and not only the person with a communication impairment (Clarke and Wilkinson, 2008; Norén, Svensson and Telford, 2013). Research 
using the method has demonstrated that co-construction of meaning is an overwhelming feature of aided interaction. An example of co-construction is the frequently occurring turn-design phenomenon of 'voicing' (Sigurd Pilesjö and Rasmussen, 2011). When doing voicing, the communication partner articulates aloud what the person with a CCN indicates on a communication device, and thus animates the aided turn without taking authorship of it, or responding to it. Furthermore, studies have shown that embodied resources are important for managing turn-taking in aided interaction (Sigurd Pilesjö and Rasmussen, 2013; Wilkinson, Bloch, and Clarke, 2011), and that AACusers' timing of their contributions plays a crucial role when accomplishing social action (Clarke and Wilkinson, 2010).

When using communication devices, participants' sequential organization of their interactions has also been demonstrated to be a crucial factor for meaning-making processes. Research on aided communication has found that communication partners exploit the sequential and projectable aspects of talk when making sense of aided turns (Clarke and Wilkinson, 2007). Commonly, the communication partner initiates a first pair-part, thereby anticipating an answer by the person with CCN, which makes the contribution more easily understood. First pair-part initiations seem to make the interaction work more smoothly. Sequentiality may also hinder meaning-making. When the individual with $\mathrm{CCN}$ changes the topic or replies in a non-projected manner, it has been found to challenge common understanding (Bloch and Wilkinson, 2004).

In a study of AAC instruction in an everyday context, Sigurd Pilesjö and Norén (2017) investigated the interaction between a girl with CCN and a speech and language therapist (ST) in a multiparty setting. The analysis demonstrated that the ST initiated and invited the child to participate in the ongoing communicative activity by way of a systematic design of interactional spaces, in which using a communication board was made relevant by employing linguistic and embodied methods and sequentially relevant changes in the participation framework. Two types of modeling strategies were used as part of this practice; indication modeling, when the ST indicated on the communication board, and simulated indication modeling, when the ST took the child's hand and indicated a symbol on the board for them. Both types seem to provide the child with models of AAC use, but in different sequential positions (first and second).

In a recent CA-related study, Clarke, Soto, and Nelson (2017) analyze and discuss recasts in interactions involving children with CCN using communication devices. They define recasts as speaking partners' immediate responses to a child's turn, which employs lexical items from the turn by the child, alters at least one of these, and provides an improved or contrasting form of the 
child's aided turn. The authors found that the children treated recasts as otherinitiations of correction or requests for confirmation. The child paid attention to the facilitator's reformulation and spontaneously used the same form later in the conversation to a higher or lesser degree, but self-corrections were often done in the next turn. The authors suggest that adults' responses to children's/ learners' aided turns provide a promising sequential context for the scaffolding of children with CCN's language development, but it should be noted that the presented recasts were only spoken turns, never combinations of speech and aided means.

Some voices within the AAC field have raised concerns about the empirical robustness of notions and concepts used within instructional practices in terms of what they actually refer to in the data. Goldstein (2002) recommends caution when reading intervention studies for inconsistently described treatment components, and Binger and Light (2007) identify a lack of knowledge of certain types of use of aided means. Kaiser and Roberts (2011) request more thorough research into the ways facilitators use aided means in natural environments, and Snell, Chen, and Hoover (2006) argue that the role of the facilitator is not thoroughly investigated in intervention studies.

Thus, although research has provided ample evidence for the effects of facilitators' use of aided means on the development of communication in children with CCN, and the strategy is recommended widely in speech and communication instruction, there is a need for more detailed descriptions of these practices, with a focus on the interactional process in a natural context and not solely on the child. Detailed analyses of speaking partners' use of AAC methods in everyday interactional contexts should increase the ecological validity of the concepts and practices used in interventions by facilitators (e.g., parents, professionals), as well as increase the possibilities for comparing intervention methods (Jonsson et al., 2011; Snell et al., 2010).

\section{Study aims}

As mentioned above, repeats, recasts, and reformulations are considered to give opportunities for children to learn language, and are commonly used in language instruction in general and in the field of AAC. To add further knowledge concerning facilitators' use of communication devices in AAC instruction in a natural context, with a specific focus on the interactional process, the aim of this study is to investigate how facilitators use aided means following aided turns by children relying on AAC systems in everyday interactions. The research questions were as follows. 
1. Which social actions do the facilitators achieve when using aided means in turns that follow an aided turn by the child?

2. How do the children respond to and treat the facilitators' aided turns in the immediately following context?

\section{Method}

\section{Analytical approach}

The research method of conversation analysis (CA) was used to investigate the research questions (Sidnell and Stivers, 2014). Conversation Analysis is a theory and method that deals with the detailed multimodal organization of interaction. The overall goal of CA is to discover how participants organize and manage interaction as a dynamic and collaborative process (Schegloff, 1996). No contribution can be understood in isolation, and the researcher can only decide what action an ongoing utterance or embodied/aided contribution achieves by observing how it is responded to (treated) in subsequent turns. This is referred to as the next-turn proof procedure (Sidnell, 2014: 79). By using this procedure, the researcher can analyze what interactional consequence a specific turn has for the following turn. In CA, video or audio recordings of everyday interactions are used as data. In this study, the principles of CA were used for collection, transcription, and analysis of data.

The notion of repair is relevant for the current study. In CA, repair refers to a set of interactionally organized practices that make the progress of the interaction go smoothly and maintain or restore intersubjectivity when there is some kind of trouble related to speaking, hearing, or understanding (Kitzinger, 2014; Schegloff, Jefferson, and Sacks, 1977). Repair has been found to be initiated and/or produced by either the speaker (self) or the communication partner (other). With regard to instances when the communication partner initiates repair (other-initiation), there is a range of different constructions. One is called a candidate understanding. Candidate understandings consist of a reformulation of the unit that is causing the trouble (trouble source). Candidate understandings are commonly framed by 'you mean' followed by the reformulation. The candidate understanding has the objective of carrying out a check of understanding with the speaker of the trouble source (Kitzinger, 2014). In child language learning research, reformulations are commonly called recasts, as mentioned above.

In addition to reformulation, a repair can also be designed as a (other) repeat of the trouble source (Kitzinger, 2014). Repeats can function as alignment, requests for clarification and requests for confirmation, and as a display that the communication partner has understood what was just said (Schegloff, 
Jefferson, and Sacks, 1977). Speech and language therapy with children and, in general, adult-children talk, contain a lot of repeats and reformulations by both participants. Repair phenomena, involving repeats, reformulations, and recasts, are analysed in terms of retro-sequences, as they can expand an ongoing interactional sequence retroactively without being projected as a relevant next action (Schegloff, 2007). In this sense, they are different from responses, which are locally projected actions.

\section{Participants}

The data consist of video recordings of, in total, nine children interacting with their everyday communication partners, but instances of facilitators' use of the communication aid following a child's aided turn were only found in interaction with four of the children. All nine children had CCN caused by cerebral palsy. The children were emerging communicators or situation-dependent communicators (Blackstone and Hunt Berg, 2003). They used Blissymbolics (McNaughton, 1985), letters, or Widgit symbols (www.widgit.com) as AAC modes stored on both low- and high-tech communication devices. The children indicated symbols on the devices using direct selection with finger/ hand (on manual board or touch screen) or eye tracking. The facilitators indicated symbols on the devices using direct selection, scanning, or pointing with a finger. They had varying degrees of training and experience of AAC interaction.

The following descriptions of participants will focus on data on interaction with the four children where facilitators used the communication device following a child's aided turn. The ages of the four children at the time of the video recording were 10;4 (Maria), 11;10 (Bert), 12 years (Anton), and 8 years (Eric). The facilitators were a mother, a grandmother, caretakers, teachers, and an ST. The instances analyzed in the Results section below consisted solely of interactions using low-tech communication boards (henceforth called devices).

\section{Data collection}

The whole data set was collected by the authors in two different video-ethnographic research projects (a $\mathrm{PhD}$ project and a post-doctoral project), which focused on interactional patterns between children with CCN and their everyday communication partners in mundane settings. Video recordings were made with one or two cameras in different locations: the children's homes, at the grandparents' house of one child, at school and at after-school care. The recordings amount to approximately 41 hours. The participants did not receive any specific instructions about what to talk about. In excerpt 1 , the child (Maria) and the special education teacher $(\mathrm{TCH})$ practiced the use of 
a bliss board by engaging in a play activity at school. In excerpt 2 , the child (Maria), her grandparents (GM and GF), and a speech and language therapist (ST) practiced the use of a bliss board at the grandparents' home. In excerpt 3 , the child (Eric), his two friends, and their ST used bliss boards during a conversation group session. In excerpt 4 , the child (Bert) and his assistant (AS) used a bliss board when chatting during recess at school. In excerpt 5, the child (Anton) and his two teachers (Ulf, T1 and Eva, T2) used a bliss board when chatting in between two lessons at school. For further information about the settings, see Appendix 2, Table A1.

There were nine instances where facilitators used the communication device following a child's aided turn. We chose to present a detailed analysis of five instances that were representative of the nine instances. The nine instances have all been analyzed into two types of techniques of using the aided means by the facilitator.

\section{Transcription procedure and conventions}

The video recordings of the whole data set were reviewed by the authors, and instances where the facilitator used the communication device following aided turns by the children were noted and thereafter transcribed. The transcriptions include multimodal phenomena, including talk, embodied behavior, and indications (pointings) on the communication device, using a combination of CA conventions (Ochs, Schegloff, and Thompson, 1996) and AAC conventions (von Tetzchner and Basil, 2011). For transcription notations, see Appendix 1.

\section{Ethical considerations}

Two projects have been ethically approved. Maja Sigurd Pilesjö, 2009-61, was approved by the Regional Ethics Board in Lund, Sweden, February 10, 2009 and by the Danish Data Inspection Board in March 2009 (Sigurd Pilesjö, 2014). Project 2, 2008/169, was approved by the Regional Ethics Board in Uppsala, Sweden, June 25,2008 . The children in the studies gave their informed consent using graphic AAC modes. In addition, the parents of the children gave their informed consent.

\section{Results}

The analyses reveal that facilitators combine speech and pointing at the communication device with a range of communicative modalities. We choose to call this practice speaking and pointing (hereafter, SAP or SAP unit). When SAP units are part of turns, we call the turns SAP turns. SAP units occur in 
different types of sequences of social action. SAP units that repeat single words in the child's aided turn were treated by the participants as requests for confirmation of a candidate understanding. SAP units that reformulate single words in the previous turn were treated by the participants as proffering a candidate understanding.

\section{Candidate understandings: Repetitions followed by embodied next moves}

A recurrent action context for the speaking partner's use of the communication device following an aided turn is a request for confirmation about the action of the aided turn. The child's aided word is repeated and exposed with a SAP, constructing a retro-sequence, that is, it is not projected. In retrospect (Schegloff, 2007), these actions construct the child's aided turn as noticeable by the speaking partner.

An instance of exposing an aided word is demonstrated in excerpt 1 . The initial initiation by the child with a CCN is brought about by several preceding questions, and in this instance the child's aided answer disaligns with the proposed options in these questions. Maria (M) and her special education teacher $(\mathrm{TCH})$ are engaged in a pedagogical play activity, where they practice using the communication board. The communication board (cbd) with bliss words is located in front of them on a table. The teacher asks Maria whether she wants to have the boat or the book, and Maria responds by indicating 'FOOD' (a third option) on the communication board with increased affect (a rather loud vocalization) (line 1). The teacher gazes at Maria and then just voices 'food' (Sigurd Pilesjö and Rasmussen, 2011) in line 3, and Maria confirms the voicing by vocalizing and raising her head (line 4 ).

\section{Excerpt 1}

1. M: $\nabla$ MAT

FOOD

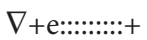

$\nabla(($ gazes at cbd $))$

2. TCH: ((gazes at cbd))

3. $\mathrm{TCH}: \uparrow \operatorname{mat} \uparrow$

$$
\text { food }
$$

4. M: ehduh ((raises head))

5. TCH: vill du ha mat. do you want food

6. TCH: MAT MAT MAT $>>>>\nabla \# 1>$ FOOD FOOD FOOD. 
7. $\mathrm{M}: \quad->$ huh $(($ touches cbd w. fist $))$

8. TCH: ((moves cbd))

9. M: $\rightarrow+$ e:i:eh+

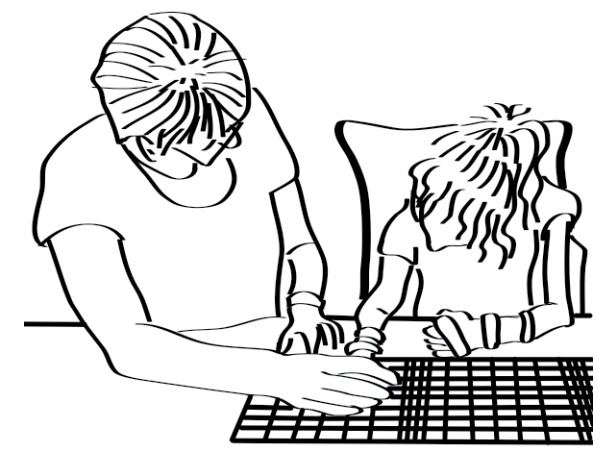

Figure 1. The facilitator points at 'FOOD' on the board and then says 'food' while maintaining the pointing.

After the confirmation (line 4), the teacher asks 'do you want food' (line 5). The turn is expanded by three pointings at the graphical word 'FOOD' (line 6). The teacher's finger stays on the word for a while, and then she repeats the spoken word 'food' while still pointing to 'FOOD.' The facilitator speaks and at the same time points to a graphic word representation on the child's communication device. It is a recurrent and systematic practice that, as already mentioned, we call a speaking and pointing action (SAP) (see Figure 1). The turn that involves a SAP unit is immediately followed by Marias confirmative response (lines 7 and 9). The confirmation closes the sequence, and the teacher then moves the communication device in alignment with that.

The facilitator proffers a possible understanding of the prior turn by repeating the child's previous one-word indication and uses SAP to highlight the child's aided word and to expose the word in the response question. The SAP turn is incrementally and multimodally produced, initiated by a spoken question, continued with repeated pointings at the symbol, and ended with the SAP. When the sequence is closed with a minimal confirmation, the SAP turn is treated as a candidate understanding and a request for confirmation by the child.

A second instance of a repeating SAP treated as a request for confirmation of a candidate understanding is demonstrated in excerpt 2 . This question features some different construction methods of the SAP unit in comparison with excerpt 1 . The girl Maria (M) is conversing with the speech and language therapist (ST) and Maria's grandparents (grandmother $=\mathrm{GM}$ ). The communication device with bliss words is located in front of them on the kitchen table. 
The grandmother asks Maria what she wants to drink, and she requests that Maria indicate her answer on the board. The girl answers and grants the request in line 1 , and the ST voices the indication in line 2.

\section{Excerpt 2}

1. M: SAFT

\section{LEMONADE}

2. ST: $s \uparrow \underline{\text { aft }}$

lemonade

3. ST: ((leans in to gaze at $\mathrm{M})$ )

4. M: ((raises head, gaze on GM))

5. GM: ((leans in and looks at cbd))

6. GM: \#2 $\nabla$ saf $\lceil$ t? ((turns to M))

lemonade
LSAFT
LEMONADE

7. M: -> Lrheheऍ he: ((gaze at GM))

8. ST: Lvill du ha.

9. GM: $\uparrow \mathrm{ja} \uparrow(($ gaze at $\mathrm{M}))$ you want

yes

The girl displays an acceptance by looking up at her grandmother again (line 4). Next (in lines 3 and 5), the ST and the grandmother look closely at Maria and the communication board, and the grandmother repeats 'lemonade' with a final high pitch while indicating 'lemonade' on the communication board - a SAP (line 6, see Figure 2). The repeat of the girl's indication and the ST's voicing, combined with high pitch and gaze, is treated by Maria as if the grandmother is doing a request for confirmation of a candidate understanding, a checking of understanding. At this point, Maria immediately confirms the

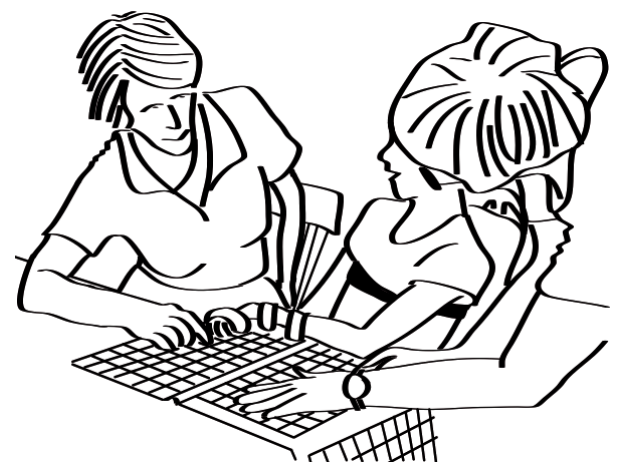

Figure 2. The facilitator says 'lemonade' while pointing at 'LEMONADE' on the board. 
request vocally (line 7 ). The ST extends the speaking and pointing response into a declarative clause (line 8). The grandmother acknowledges Maria's confirmation with 'yes' (line 9), which closes the sequence.

As in excerpt 1, the facilitator uses SAP to highlight the graphical word in a request for confirmation of a candidate understanding: the facilitator repeats the child's aided word. While gazing at the child with a $\mathrm{CCN}$, the facilitator uses a high pitch voice to expose the SAP, and the ST expands the SAP unit into a declarative and confirming comment. The SAP turn is treated as a request for confirmation of a candidate understanding by the child when confirming with vocalization and gaze at GM, and Maria's response closes the sequence.

\section{Candidate understandings: Reformulations followed by device- mediated next moves}

A second set of instances of responses to children's aided turns using SAP were embedded in turns that were treated as a proffering of a candidate understanding, rather than as a request for confirmation. In excerpt 3 , three boys engage in a conversation group session together with a speech and language therapist (ST). They have previously talked about family members, and one child has just told the group that he has a brother. Then the ST asks Eric if he has one brother, and Eric answers with a vocalization 'eh' and an indication of the bliss word 'GIRL' on the board (line 1).

\section{Excerpt 3}

1. E: eh FLICKA

GIRL

2. ST: en ((leans over twd cbd 2.0)) <flicka>.

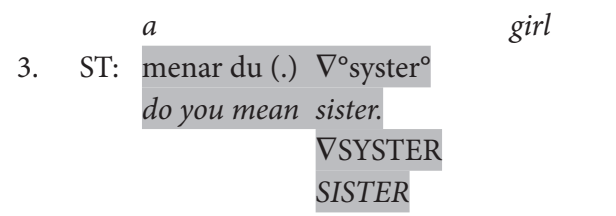

4. E: -> DSYSTER

SISTER

$\nabla$ eh

5. ST: en $\underline{\text { syster }}$

a sister

The ST initiates a voicing of Eric's aided turn with 'a', leans over to look at the communication board, and then finishes the voicing with a prosodically extended 'girl' (line 2). Next, the ST asks Eric 'do you mean sister.' When saying 'sister' with reduced volume, the ST points at the symbol/word 'SISTER' - a 


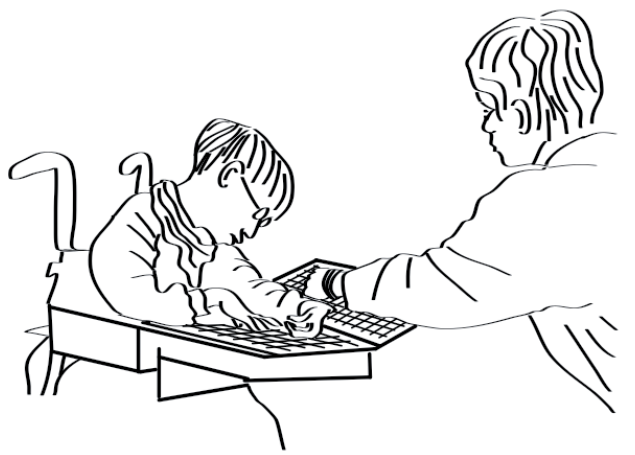

Figure 3. The facilitator says 'sister' while pointing at 'SISTER' on the board.

SAP turn (line 3, see Figure 3). The ST's turn proffers an alternative to Eric's augmented word 'GIRL,' a candidate understanding. After the proffer, the boy indicates 'SISTER' (line 4), doing the repair and closing the sequence.

As in excerpts 1 and 2, the facilitator uses SAP to highlight the target word in the responsive question, but here the word is a replacement of the child's aided word. The SAP turn is constructed with the phrase 'do you mean' together with a possible understanding, proffering a replacement of the word in the prior turn and providing a candidate understanding. It is preceded by a short pause and is prosodically subdued. The two resources work together to expose the SAP unit. The SAP turn is treated by the child as an acceptable candidate understanding when repeating the replacing word on the device and thereby closing the sequence.

In excerpt 4, the child Bert (B) begins to construct an aided turn in line 1. Bert's aided turn is an initiative in which he comments on (or possibly requests) something in relation to previous talk on upcoming events during the week. Bert has indicated 'YOU-Helena-HOUSE' on his communication device. Bert's assistant (AS) has some trouble understanding the aided turn beginning, and in line 9 (instead of voicing the previous pointing at herself individually), she asks a question about the possible meaning of the aided turn beginning and proffers a candidate understanding of it ('do you mean home at my place,' lines 9-10). When uttering 'home,' she also points at the symbol 'HOME' - a SAP turn (see Figure 4).

\section{Excerpt 4}

1. B: (DU)

YOU

2. AS: jag,

me

3. B: ((points at AS)) 
4. AS: Helena,

5. B/AS: ((mutual gaze))

6. B: (HUS)

(HOUSE)

7. AS: hus.

house

8. B: ((points and gazes at AS))

9. AS: menar du $\nabla \# 4$ hemma hos mig

do you mean home at my place.

$\nabla$ HEMMA >

HOME

10. B: -> (IN) ((gazes at AS))

IN

11. AS: inne,

inside

12. B: $\quad(($ gazes at AS, lifts hand $))$

13. B: ((points at AS))

14. B: HUS

HOUSE

15. AS: (inne i huset).

inside the house

16. B: PAPPA

$D A D D Y$

17. AS: $\uparrow$ pappa $\uparrow$

Daddy

The assistant's turn reformulates the child's aided turn, combines the previous moves by Bert ('YOU + Helena + HOUSE + pointing at AS') and replaces the word 'HOUSE' with 'HOME', constructing it into the candidate understanding 'at my home/HOME. The candidate understanding is performed with the

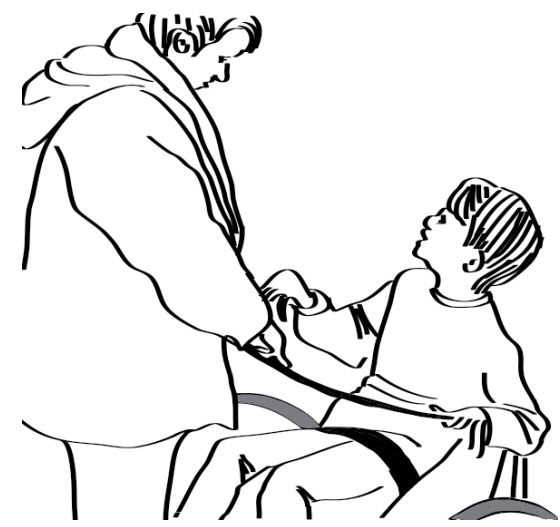

Figure 4. The facilitator says 'home' while pointing at 'HOME' on the board. 
common format 'do you mean' + replacement word as in excerpt 3 (Kitzinger, 2014). Instead of accepting the proffered candidate understanding with the candidate term (as in excerpt. 3), Bert rejects it. He reformulates and expands his aided turn in the next position. He continues with ' $I N$ ' that is voiced as 'inside' (lines 10-11), and then repeats his previous combination 'point at AS + HOUSE' (lines 13-14). The subsequent voicing 'inside the house' appears to combine 'IN + point at AS + HOUSE' (line 15). Bert seems to accept the voicing when moving on to the next aided word ' $D A D D Y$ '.

As in excerpt 3, the facilitator uses the reformulation SAP to highlight a replacement of the child's aided word. The SAP proffers an alternative word placed within a turn final noun phrase, 'home at my place', but the SAP unit as such ('home/HOME') is placed in a turn medial position and is not prosodically exposed. Thus, the pointing work alone exposes the graphical word. The SAP turn is a candidate understanding, offering an alternative formulation, which is rejected by the child. Both excerpts 3 and 4 are constructed with the phrase 'do you mean' + a replacement word in an interrogative format.

The last excerpt (5) contains two instances of SAP. The first SAP reformulates and other-corrects the child's preceding aided word, and the second repeats the child's preceding aided word. In the excerpt, Anton and his two teachers, Ulf (T1) and Eva (T2), are talking in between school sessions. Anton has indicated VI VÄNTAR PA (WE ARE WAITING FOR) on the device, and Ulf summarizes Anton's turn so far in line 1, prompting him to continue. Anton continues with the word ZERO (line 3), and after the voicing by Eva, Ulf responds by asking 'or is it for thera- (1.0) is it therapist' (lines 5-6). The two symbols ZERO and THERAPIST are located next to each other on the board, and Ulf proffers an alternative word and possible correction in orientation to his knowledge about Anton's day schedule - he has an appointment with the physiotherapist.

\section{Excerpt 5}

1. T1: vi: väntar på:

we are waiting for

2. A: ((holds hand over cbd 3.0))

3. A: .......NOLL

ZERO

4. T2: noll.

zero

5. T1: TERAPEUT $\nabla>>>>>>(1.0)=$ THERAPIST

$\nabla$ eller e're på tera-

or is it for thera-

6. $\mathrm{T} 1:=>>\# 5 \mathrm{ab}>>>$

$=$ 're terapeut.

is it therapist 
7. A:-> NOLL

\section{ZERO}

8. T2: ${ }^{\circ o}$ nej $^{\text {oo }}(($ shakes head $))$

no

9. T1: nej de e $\nabla$ noll.\#5cd

no it's zero

\section{$\nabla$ NOLL \\ ZERO}

10. A:-> NIO

NINE

11. T1: nie,

nine

12. A: ((removes hand from cbd))

Ulf's follow-up turn was initiated with a pointing at the bliss word 'THERAPIST,' and then developed by the spoken question, and ended with the replacement word 'therapist' (Ulf holds his thumb on the symbol during the whole turn) a SAP turn (see Figures 5a and 5b).

The whole turn proffers a replacement and other-correction of ' $Z E R O$ ' with the graphical word 'THERAPIST,' and the final SAP unit exposes that replacement. However, Anton rejects the other-correction by repeating his indication of 'ZERO' (line 7), thereby launching an other-correction of his own. The teachers' responses in lines 8 and 9 (' $n o$ ' and 'no it's zero') acknowledge Anton's rejection (and other-repair) and also re-voice his indication.

As in excerpts 3 and 4, the facilitator used the reformulating SAP in lines 5-6 to highlight a replacement of the child's aided word, but here the reformulation proffers a candidate understanding that initiates an other-repair and identifies a trouble source, an assumed mistake when indicating on the device.

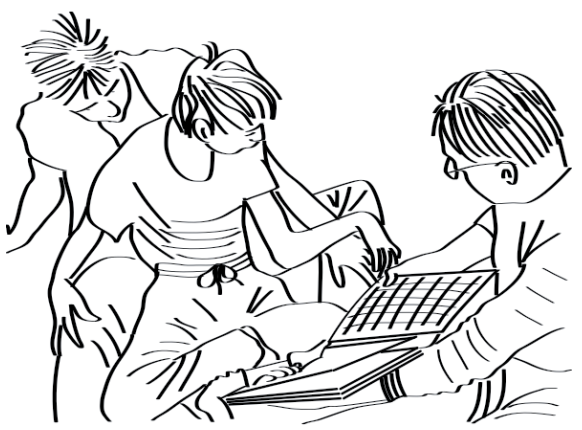

Figure 5a. The facilitator points at 'THERAPIST' on the board and then says 'or is it on thera- is it therapist' while maintaining the pointing.

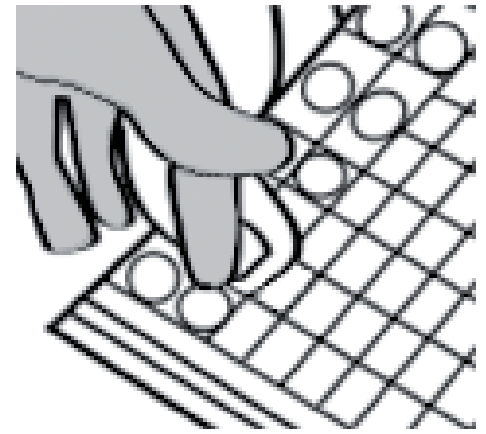

Figure 5b. Close-up on the facilitator's pointing at 'THERAPIST' on the board. 


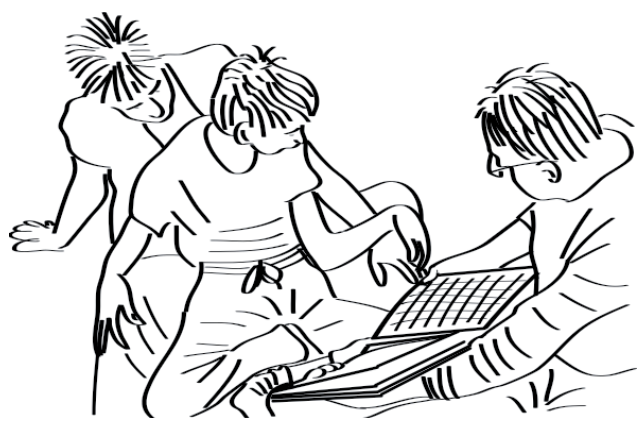

Figure 5c. The facilitator says 'zero' while pointing at 'ZERO' on the board.

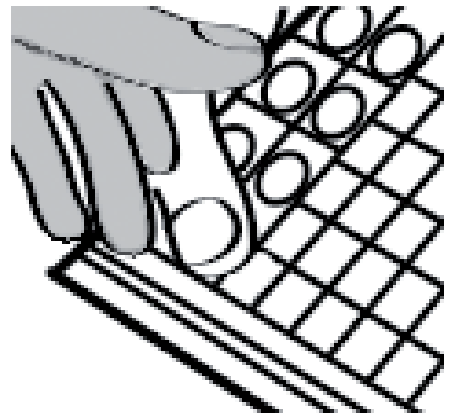

Figure $\mathbf{5 d}$. Close-up on the facilitator's pointing at 'ZERO' on the board.

When Anton repeated his aided word, the candidate understanding and correction were rejected. The communicative modalities within the reformulating SAP turn were differently organized compared to previous extracts. Here, they were organized with an initial pointing at a graphical word as a way to claim the turn, then maintaining the pointing while continuing with a spoken question, and finally ending the spoken question with a word that combined with the graphical word in a turn final SAP.

Ulf's self-repair in line 9 was a repeating SAP turn (see Figures $5 c$ and $5 d$ ), which voiced the child's previous aided turn and closed the overall repair sequence.

This resembles the SAP turns in excerpts 1 and 2, but here Anton did not treat the repeating SAP as an explicit request for confirmation of an understanding. Instead, he just accepted Ulf's re-voicing by moving on with the next word 'NINE' in his aided turn (line 10). As in excerpts 1 and 2, the facilitator used the repeating SAP in line 9 to highlight the child's previous aided word in a confirming and declarative comment where the SAP unit was placed turn final, which closed the sequence.

In sum, the analysis has demonstrated six instances (in five excerpts) where the facilitator uses aided means within the local context of retro-sequences, following an aided turn by the child with a CCN. The use was always combined with speaking and we call the practice speaking and pointing (SAP). A first set of SAPs achieved highlighting of a word in the previous aided turn and were treated by the child as requests for confirmations of candidate understandings. These actions were designed as other-repeats of the aided word in the prior aided turn and closed the sequence. The children responded to SAP repeats with vocal and embodied confirmations. 
A second set of SAPs achieved highlighting of and proffering a potential replacement of the aided word in the prior turn. The child treated these SAP turns as proffering candidate understandings or doing other-repair. The candidate understandings and the other-repair were designed as reformulations, and were responded to by the child by either accepting or rejecting, involving the use of the device. The child accepted the replacement word by repeating the proffered aided word.

In rejections of the SAP reformulation, the following aided turn by the child was either a repeat of the child's prior turn or an expansion with other aided words. An accept closed the sequence, but a rejection projected further topical talk and use of the device by the child. The speaking and pointing practices were designed as a combination of multimodal means: speaking and pointing at one word in the spoken turn. This was accompanied by expanding talk that contributed to specifying the action of the response together with the overall sequential organization. The repeated pointings at a graphic word (as in excerpt 1) worked to upgrade the emphasis of an already stressed aided word and pursued a response from the child. The speakers also used prosodic means to mark and expose the SAPs, such as minimal pauses just before the SAP, high pitch or decreased volume on the SAP. The SAP unit was initial in some SAP turns, and final in others, depending on the clause type (syntactic interrogatives in Swedish are always verb initial with nominal units in later positions, while word order in declaratives is more flexible). All the SAPs included an indication on a single graphical word: in these data noun. Some SAP turns were initiated by pointing, and then speech was added in a turn extension ending with a SAP (excerpt 5, lines 5-6). Some SAP turns were initiated by the SAP unit and extended with speech (excerpt 2), but the most common production method was to begin the turn with speech and then highlight a particular word with the SAP later on in the turn.

\section{Discussion and conclusions}

The analyses demonstrate that facilitators' active use of the communication aid - a speaking and pointing practice - immediately after an aided turn by the child materializes as different conversational practices, which are treated in different ways by the child. The facilitators use two main techniques when using the communication device: repeats and reformulations. The children treat repeats as requests for confirmation of a candidate understanding and respond minimally without using the board (initiating sequence closure) (excerpts 1, 2, and 5). The children treat reformulations with profferings of potential replacement words as candidate understandings or correction, which 
are either accepted by the child as they repeat the proffered substituting word with the device (closing the sequence), or rejected by the child when they restart the aided turn and expand the sequence or when they defend the first aided word by repeating it (excerpts 3, 4, and 5).

In general, the pointing part of the SAP contributes to acknowledging that the child's previous aided turn was a noticeable and relevant action. More specifically, facilitators' use of a communication device brings together multimodal resources such as different clausal constructions, different prosodic resources, and graphical means. Spoken clausal constructions such as declaratives or interrogatives are intertwined with graphical indications. No instances have been observed where facilitators use aided means without accompanying talk. In excerpt 2, the facilitator utters only the spoken word of the indicated word ('lemonade'), but another speaker then expands this word into a declarative clause. In excerpts 1, 3, 4, and 5, the facilitator merges the pointing at one graphical word with a multi-word spoken turn. The spoken turns carry more linguistic content, but the use of the aided means achieves a focus on a particular word in the following turn as well as in the preceding turn. The social action is achieved together with the child's immediate response to the SAP turn.

The SAPs that replace an item in the previous aided turn (e.g., 'GIRL' to 'SISTER') provide an alteration (a recast) of the meaning of the child's linguistic item. It provides a version that adheres more to an adult norm in relation to the ongoing topic (excerpt 3). Compared to Clarke, Soto, and Nelson (2017), who also investigated recast (reformulation) responses to aided communicators' turns, the children in our data seem to treat these responses differently. In their data, the children treated recast responses as both requests for confirmation and initiations of other-correction, using only minimal resources (vocalizations and embodied means) in their immediate third-turn responses when confirming. In our data however, reformulation SAPs, although only numbering three occurrences in total, were treated as initiations of other-repair in which the child used graphical resources to accept or reject the proffered replacement words. Until further research has proven otherwise, the presence or absence of SAP in the recast responses may be a potential difference between our corpuses. Speaking and pointing seems to increase the noticeability of the replacement word in our data compared to reformulations without SAP as presented by Clarke, Soto, and Nelson (2017).

When comparing the findings of the current study with the study by Soto, Clarke, Nelson, Starowicz, and Savaldi-Harussi (2019), a few similarities are found. In our study, two children did repairs after a reformulation (excerpts 3 and 5), and in the study by Soto and colleagues the children carried out repairs 
more frequently when they were prompted to do so, that is, when the communication partner pointed at the target linguistic item on the device.

The phenomenon of SAP responses to aided turns (both repeating and reformulating variants) is interesting in relation to the concept of recast within the tradition of developmental psychology. It has been noted by researchers on $\mathrm{AAC}$ and language intervention that these terms are vague and refer to several different practices, and therefore are in need of more detailed empirical analysis. The SAPs in our data draw attention to single linguistic items with varying consequences for the unfolding interaction. In only one of the six instances did the child actually use the SAP-highlighted word in the next turn. Thus, the analysis in the current study does not lend support to the idea that all SAPs in responses to aided turns actually work as models of device use in the local sequential context. However, the sequential context of proffering a candidate understanding, designed as a reformulation, seems to provide a context for communication device use.

Our study demonstrated that facilitators' speaking and pointing practices achieve joint attention to the device, and these practices were treated by the children as requests for confirmation or other-initiated repair of the children's own aided turns. This can be regarded as a collaborative practice, achieving a moderate to high degree of noticeability of the children's aided actions. The practice constructs a local sequential context for joint focus on a particular word in the child's previous turn. With a focus on AAC interaction rather than on AAC modeling or AAC use, these aspects of the practice could work to support language acquisition (also see Clarke, Soto, and Nelson, 2017, and Soto, Clarke, Nelson, Starowicz, and Savaldi-Harussi, 2019, for similar ideas).

\section{Clinical implications and future directions}

The current analysis of SAP in everyday interaction demonstrates aspects of the practice that seem beneficial for AAC instruction. The SAPs in our data attract attention to a specific graphical word when exposing and emphasizing it. The SAP turns treat the child's previous aided turn as relevant and meaningful when asking questions about it or commenting on it. For clinicians, it can be useful to be aware that the child with CCN may treat facilitators' use of augmentative means differently. A repeat may be responded to as a request for confirmation of an understanding with embodied means. A reformulation as a candidate understanding (where the child can choose to accept or reject a suggested word) may be responded to with the device. In this way, the facilitator can shape the interaction differently depending on what they want to achieve. The use of aided means when repeating and reformulating previous 
indications highlights the graphical words for the children, and hence the use of aided means contributes to the formation of different social actions (Schegloff, 2007).

The focus of SAP units on single linguistic items in our data is in strong contrast to intervention contexts that have focused on grammar (e.g., Binger and Light, 2007; Binger, Maguire-Marshall, and Kent-Walsh, 2011; Bruno and Trembath, 2006). However, SAPs with multiple linguistic elements could have occurred, because some of the children produced multi-word aided turns. When proffering alternative understandings of the children's aided multiword turns (in excerpts 4 and 5), the practice of SAP, from a technical and pedagogical point of view, could have been employed on all words in the following turn, but there was no apparent interactional relevance of highlighting more than the single repeated or reformulated word in the ongoing activity.

According to previous research on AAC, children and young adults with $\mathrm{CCN}$ lack exposure to the AAC modes that they are expected to use as an augmentative resource themselves (Romski and Sevcik, 2003). In our study, this is the case when the learner is expected to be above the one-word level. Most of the instances including a SAP were observed in the data with Maria, who is by far the least advanced communicator in our study. It then seems logical that the speaking and pointing practices are only used for one linguistic item/symbol. However, since they have the ability to use multi-word turns, the other children in the data would probably benefit from speaking and pointing practices for more than one graphical word. In an everyday setting, however, unless a communicative need emerges within the unfolding interaction to ask questions or initiate other-repair, multi-word SAPs appear to be less relevant in retro-sequential positions.

Finally, the detailed sequential analysis of the observed practices contributed to more precise descriptions and definitions of the investigated phenomenon. In studies of AAC, intervention practices are often unclearly described (Binger and Light, 2007; Goldstein, 2002). This may result in difficulties in conducting and comparing interventions (Kaiser and Roberts, 2011). There is also commonly a lack of descriptions of AAC interaction and instruction in everyday contexts. The suggested terms and detailed described practices from the current study could result in more rigorous and clear intervention strategies, increasing the possibilities to perform interventions also in a natural context. We also argue that more detailed descriptions of interventions significantly improve the way in which intervention studies can be compared.

In our analyses, we focused on speaking and pointing practices that immediately followed aided turns by children with CCNs. We also found a number of instances of speaking and pointing practices in facilitators' turns that 
immediately preceded aided turns by children with CCNs. These aided turns will be explored separately.

\section{Acknowledgments}

Funding: the research was part of a larger data set, which originated from previous projects of the authors.

Declaration of conflicting interest: the authors have declared no potential conflicts of interest with respect to the research, authorship, and/or publication of this article.

\section{About the authors}

Maja Sigurd Pilesjö is a speech and language therapist and Associate Professor at the University of Southern Denmark. Maja Sigurd Pilesjö's main research interests are multimodal interaction under atypical conditions such as severe speech/ language impairment, the role of the communication partner in Augmentative and Alternative Communication (AAC) and intervention practices in AAC. She has mainly used conversation analysis and multimodal interaction analysis as a research method.

Niklas Norén is Associate Professor in Education at Uppsala University. Using the practices and principles of ethnomethodological and multimodal interaction analysis, his research concerns the organisation of interaction involving children with complex communicative needs in everyday and institutional contexts, interactional aspects of reading and writing practices in school, and interdisciplinary aspects of oral language in childrens' literacy development.

\section{References}

Acheson, M. (2006). The effect of natural aided language dtimulation on requesting desired objects or actions in children with autism spectrum disorder. Dissertation, Department of Special Education, University of Cincinnati.

Alant, E., Alshubrumi, A., and Sun, L. (2017). Use of an eight-step instructional model to train school staff in partner-augmented input shows potential. Evidence-Based Communication Assessment and Intervention, 11 (1-2), 9-13. https://doi.org/10.1080/1 $\underline{7489539.2017 .1317100}$

Allen, A., Schlosser, R., Brock, K., and Shane, H. (2017). The effectiveness of aided augmented input techniques for persons with developmental disabilities: A systematic review. Augmentative and Alternative Communication, 33(3): 149-159. https://doi.org/ $\underline{10.1080 / 07434618.2017 .1338752}$ 
Biggs, E., Carter, E., and Gilson, C. (2018). Systematic review of interventions involving aided AAC modeling for children with complex communication needs. American Journal on Intellectual and Developmental Disabilities, 123(5), 443-473. https://doi. org/10.1352/1944-7558-123.5.443

Binger, C., and Light, J. (2007). The effect of aided AAC modeling on the expression of multi-symbol messages by pre-schoolers who use AAC. Augmentative and Alternative Communication, 23(1), 30-43. https://doi.org/10.1080/07434610600807470

Binger, C., Maguire-Marshall, M., and Kent-Walsh, J. (2011). Using aided AAC models, recasts, and contrastive targets to teach grammatical morphemes to children who use AAC. Journal of Speech, Language and Hearing Research, 54, 160-176. https://doi. org/10.1044/1092-4388(2010/09-0163)

Blackstone, S., and Hunt Berg, M. (2003). Social Networks: A Communication Inventory for Individuals with Complex Communication Needs and their Communication Partners. Monterey: Augmentative Communication.

Bloch, S., and Wilkinson, R. (2004). The understandability of AAC: A conversation analysis study of acquired dysarthria. Augmentative and Alternative Communication, 20(4), 272282. https://doi.org/10.1080/07434610400005614

Blockberger, S., and Sutton, A. (2003). Toward linguistic competence. Language experiences and knowledge of children with extremely limited speech. In J. Light, D. Beukelman, and J. Reichle (Eds.), Communicative Competence for Individuals who use AAC 63-106. Baltimore: Paul Brookes.

Bruno, J., and Trembath, D. (2006). Use of aided language stimulation to improve syntactic performance during a weeklong intervention program. Augmentative and Alternative Communication, 22(4), 300-313. https://doi.org/10.1080/07434610600768318

Clarke, M., and Bloch, S. (2013). AAC practices in everyday interaction. Augmentative and Alternative Communication, 29(1), 1-2. https://doi.org/10.3109/07434618.2013.767487

Clarke, M., and Wilkinson, R. (2007). Interaction between children with cerebral palsy and their peers 1: Organizing and understanding VOCA use. Augmentative and Alternative Communication, 23(4), 336-348. https://doi.org/10.1080/07434610701390350

Clarke, M., and Wilkinson, R. (2008). Interaction between children with cerebral palsy and their peers 2: Understanding initiated VOCA-mediated turns. Augmentative and Alternative Communication, 24(1), 3-15. https://doi.org/10.1080/07434610701390400

Clarke, M., and Wilkinson, R. (2010). Communication aid use in children's conversation - Time, timing and speaker transfer. In H. Gardner and M. Forrester (Eds.), Analysing Interactions in Childhood. Insights from Conversation Analysis 249-266. Chichester: Wiley-Blackwell.

Clarke, M., Soto, G., and Nelson, K. (2017). Language learning, recasts, and interaction involving AAC: Background and potential for intervention. Augmentative and Alternative Communication, 33(1), 42-50. https://doi.org/10.1080/07434618.2016.1278130

Drager, K., Postal, V., Carrolus, L., Castellano, M., Gagliano, C., and Glynn, J. (2006). The effect of aided language modeling on symbol comprehension and production in 2 preschooler's with autism. American Journal of Speech-Language Pathology, 15(2), 112-125. https://doi.org/10.1044/1058-0360(2006/012) 
Friedland, D., and Miller, N. (1999). Language mixing in bilingual speakers with Alzheimer's dementia: A conversation analysis approach. Aphasiology, 13(4-5), 427-444. https://doi. org $/ 10.1080 / 026870399402163$

Gardner, H. (2006). Training others in the interactional art of therapy for specific needs. Child Language Teaching and Therapy, 27(1), 27-56. https://doi. org/10.1191/0265659006ct296oa

Goldstein, H. (2002). Communication intervention for children with autism: A review of treatment efficacy. Journal of Autism and Developmental Disorders, 32(5), 373-396. https://doi.org/10.1016/B978-012373606-2.50012-7

Goosens, C. (1989). Aided communication intervention before assessment: A case study of a child with cerebral palsy. Augmentative and Alternative Communication, 5(1), 14-26. https://doi.org/10.1080/07434618912331274926

Harris, M. D., and Reichle, J. (2004). The impact of aided language stimulation on symbol comprehension and production in children with moderate cognitive disabilities. American Journal of Speech-Language Pathology, 13(2), 155-167. https://doi. org/10.1044/1058-0360(2004/016)

Hepting, N., and Goldstein, H. (1996). What's natural about naturalistic language intervention? Journal of Early Intervention, 20(3), 249-265. https://doi. org/10.1177/105381519602000308

Jonsson, A., Kristoffersson, L., Ferm, U., and Thunberg, G. (2011). The ComAlong communication boards: Parents' use and experiences of aided language stimulation. Augmentative and Alternative Communication, 27(2), 103-116. https://doi.org/10.3109 $\underline{107434618.2011 .580780}$

Kaiser, A., and Roberts, M. (2011). Advances in early communication and language intervention. Journal of Early Intervention, 33(4), 298-309. https://doi.org/10.1177/ $\underline{1053815111429968}$

Kent-Walsh, J., Binger, C., and Hasham, Z. (2010). Effects of parent instruction on the symbolic communication of children using augmentative and alternative communication during storybook reading. American Journal of Speech-Language Pathology, 19(2), 97-107. https://doi.org/10.1044/1058-0360(2010/09-0014)

Kitzinger, C. (2014). Repair. In J. Sidnell \& T. Stivers (Eds.), The Handbook of Conversation Analysis 229-256. Chichester: Wiley Blackwell. https://doi.org/10.1002/9781118325001. $\underline{\operatorname{ch} 12}$

Lesser, R., and Milroy, L. (1993). Linguistics and Aphasia. London: Longman.

Lund, S. K.. and Light, J. (2003). The effectiveness of grammar instruction for individuals who use augmentative and alternative communication systems: A preliminary study. Journal of Speech, Language and Hearing Research, 46(5), 1110-1123. https://doi. org/10.1044/1092-4388(2003/087)

McNaughton, S. (Ed.) (1985). Communicating with Blissymbols. Toronto: Blissymbolics Communication Institute.

Norén, N., Samuelsson, C., and Plejert, C. (2013). Dialogical perspectives on aided communication. In N. Norén, C. Samuelsson, and C. Plejert (Eds.), Aided Communication in Everyday Interaction 1-22. Guildford: J \& R Press.

Norén, N., Svensson, E., and Telford, J. (2013). Participants' dynamic orientation to folder navigation when using a VOCA with a touch screen in talk-in-interaction. Augmentative 
and Alternative Communication, 29(1), 20-36. https://doi.org/10.3109/07434618.2013. $\underline{767555}$

Ochs, E., Schegloff, E., and Thompson, S. (1996). Interaction and Grammar. Cambridge: Cambridge University Press. https://doi.org/10.1017/CBO9780511620874

Romski, M., and Sevcik, R. (2003). Augmented input: Enhancing communication development. In J. Light, D. Beukelman, and J. Reichle (Eds.), Communicative Competence for Individuals Who Use AAC 147-162. Baltimore: Brookes.

Saxton, M. (2005). 'Recast' in a new light: Insights for practice from typical language studies. Child Language Teaching and Therapy, 21(1), 23-38. https://doi. org/10.1191/0265659005ct279oa

Schegloff, E. (1996). Turn organization: One intersection of grammar and interaction. In E. Ochs, E. Schegloff, and S. Thompson (Eds.), Interaction and Grammar 52-133. Cambridge: Cambridge University Press. https://doi.org/10.1017/CBO9780511620874.002

Schegloff, E. (2007). Sequence Organization in Interaction: A Primer in Conversation Analysis, Volume 1. Cambridge: Cambridge University Press. https://doi.org/10.1017/ CBO9780511791208

Schegloff, E. A., Jefferson, G., and Sacks, H. (1977). The preference for self-correction in the organization of repair in conversation. Language, 53(2), 361-382. https://doi. org/10.2307/413107

Sennott, S., Light, J., and McNaughton, D. (2016). AAC modeling intervention research review. Research and Practice for Persons with Severe Disabilities, 41(2), 101-115. https:// doi.org/10.1177/1540796916638822

Sidnell, J. (2014) Basic conversation analytic methods. In J. Sidnell and T. Stivers (Eds.), The Handbook of Conversation Analysis 77-100. Chichester: Wiley Blackwell.

Sidnell, J., and Stivers, T. (2014). The Handbook of Conversation Analysis. Chichester: Wiley Blackwell. https://doi.org/10.1002/9781118325001.ch5

Sigurd Pilesjö, M. (2013) On the use of bodily action and vocalizations as resources and methods when claiming and completing turns in aided interaction. In N. Norén, C. Samuelsson, and C. Plejert (Eds.) Aided Communication in Everyday Interaction 59-94. Guildford: J\&R Press.

Sigurd Pilesjö, M. (2014). Creating meaning through the coordination of gaze direction and arm/hand movement. Journal of Interactional Research in Communication Disorders, 5, 63-96. https://doi.org/10.1558/jircd.v5i1.63

Sigurd Pilesjö, M., and Norén, N. (2017). Teaching communication aid use in everyday conversation. Child Language Teaching and Therapy, 33(3), 241-253. https://doi.org/10.1177/ $\underline{0265659017702204}$

Sigurd Pilesjö, M., and Rasmussen, G. (2011). Exploring interaction between a nonspeaking boy using aided augmentative and alternative communication and his everyday communication partners: features of turn organization and turn design. Journal of Interactional Research in Communication Disorders, 2(2), 183-213. https://doi. org/10.1558/jircd.v2i2.183

Simmons-Mackie, N., and Damico, J. (2008). Exposed and embedded corrections in aphasia therapy: Issues of voice and identity. International Journal of Language and Communication Disorders, 43(S1), 5-17. https://doi.org/10.1080/13682820701697889 
Snell, M., Chen, L.-Y., and Hoover, K. (2006). Teaching alternative and alternative communication to students with severe disabilities: A review of intervention research 19972003. Research and Practice for Persons with Severe Disabilities, 31(3), 203-214. https:// doi.org/10.1177/154079690603100301

Snell, M., Brady, N., McLean, L., Ogletree, B., Siegel, E., Sylvester, L., Mineo, B., Paul, D., Romski, M., and Sevcik, R. (2010). Twenty years of communication intervention research with individuals who have severe intellectual and developmental disabilities. American Journal of Intellectual and Developmental Disabilities, 115(5), 364-380. https:// doi.org/10.1352/1944-7558-115-5.364

Soto, G., Clarke, M., Nelson, K., Starowicz, R., and Savaldi-Harussi, G. (2019). Recast type, repair, and acquisition in AAC mediated interaction. Journal of Child Language, 47, 250264. https://doi.org/10.1017/S0305000919000436

Tomasello, M. (2003). Constructing a Language: A Usage-Based Theory of Language Acquisition. Cambridge: Harvard University Press.

Von Tetzchner, S., and Basil, C. (2011) Terminology and notation in written representations of conversations with augmentative and alternative communication. Augmentative and Alternative Communication, 27(3), 141-149. https://doi.org/10.3109/07434618.201 1.610356

Widgit symbols. https://www.widgit.com

Wilkinson, R., Bloch, S., and Clarke, M. (2011). On the use of graphic resources in interaction by people with communication disorders. In J. Streeck, C. Goodwin, and C. LeBaron (Eds.), Embodied Interaction: Language and Body in the Material World 152168. Cambridge: Cambridge University Press. 


\section{Appendix 1: Transcription notations}

Transcriptions combine conventions in CA (Ochs, Schegloff, and Thompson, 1996) with conventions in AAC (von Tetzchner and Basil, 2011).

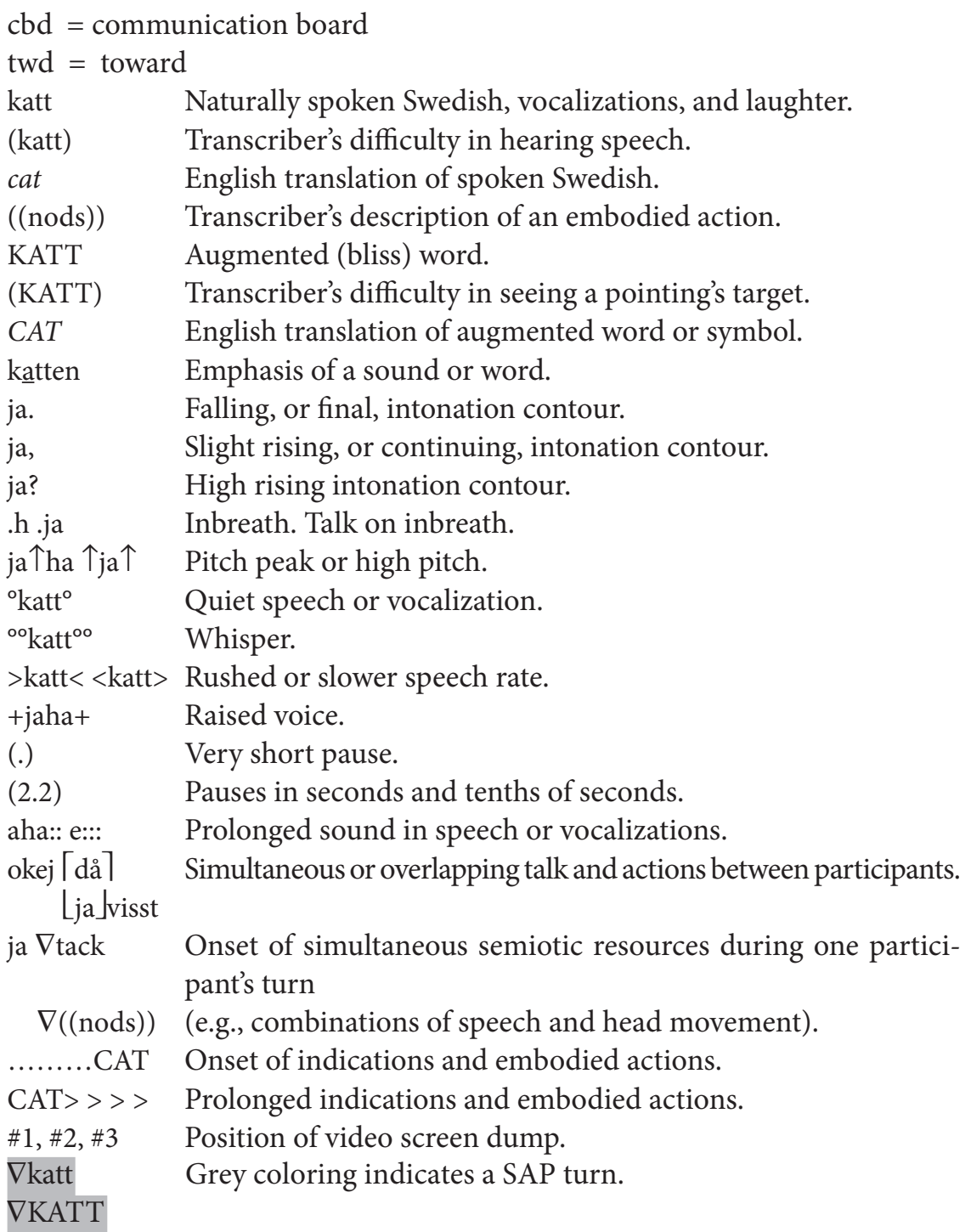




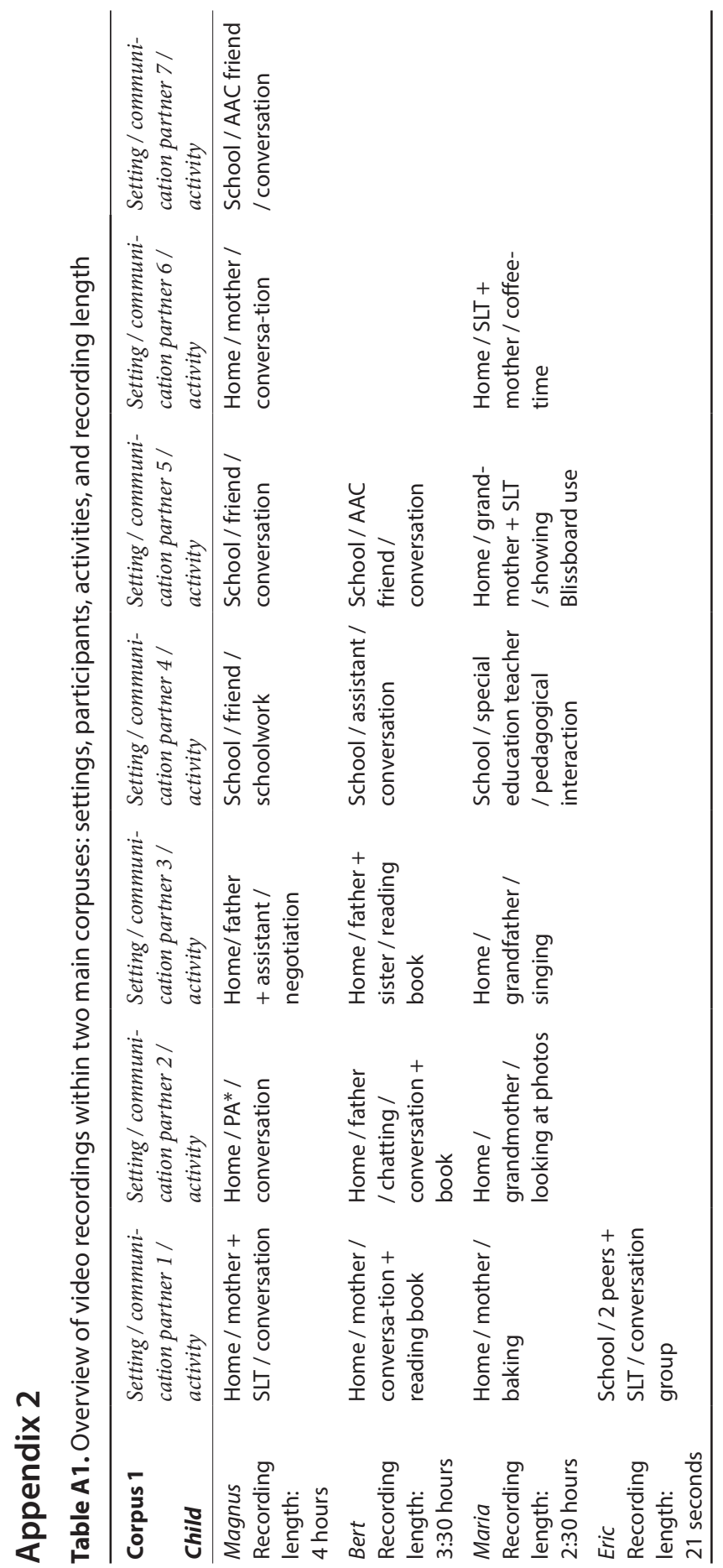




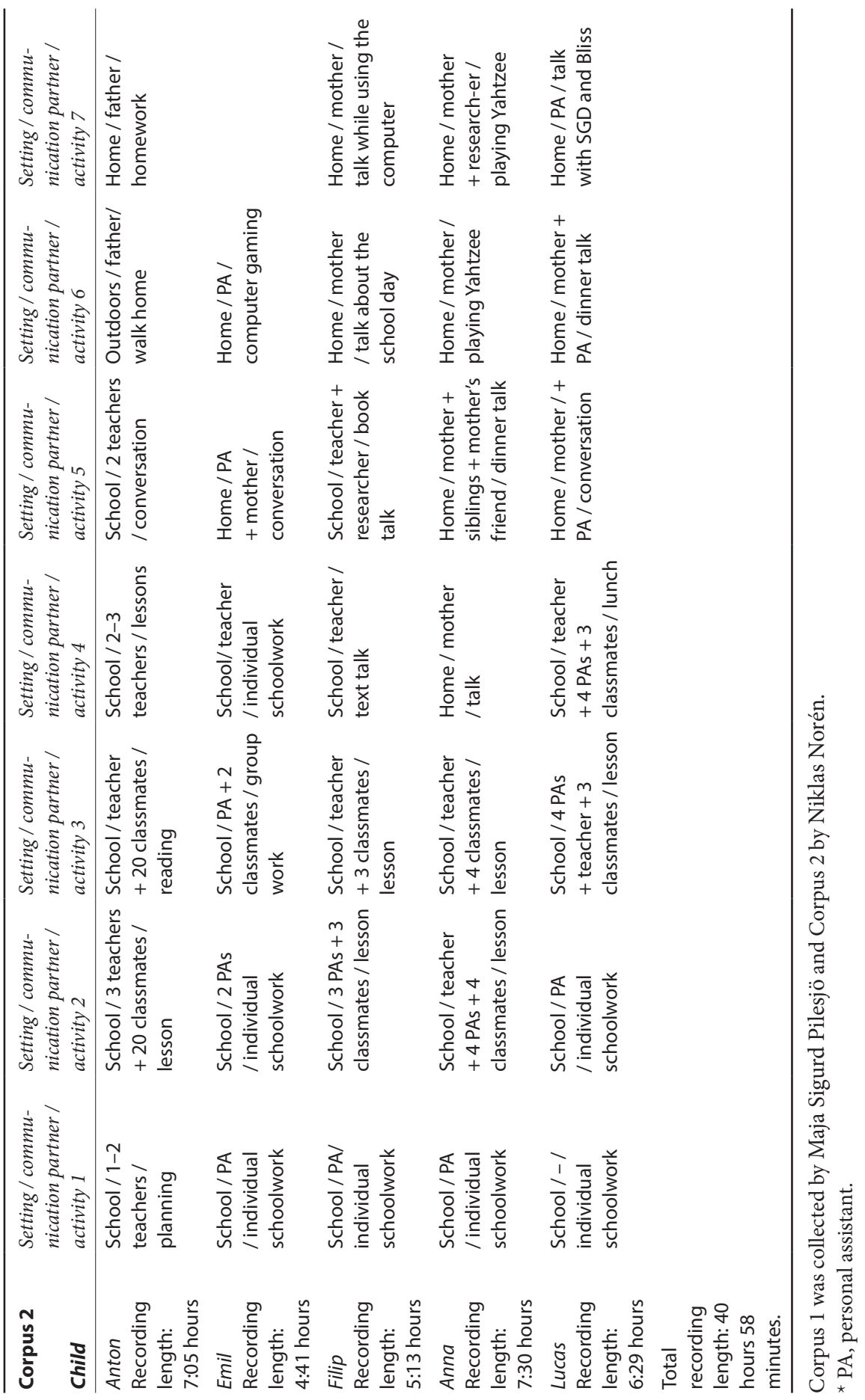


